\title{
Factors Associated with Fissure Sealant Delegation: Dentist Characteristics and Office Staffing Patterns
}

\author{
Mahassen M. Farghaly, BDS, PhD \\ W. Paul Lang, DDS, MPH \\ Marilyn W. Woolfolk, DDS, MPH \\ Barbara W. Faja, MPH \\ School of Dentistry \\ University of Michigan \\ Ann Arbor, MI \\ Thomas L. Ziemiecki, DDS, MS \\ School of Dental Medicine \\ University of Connecticut \\ Farmington, CT
}

Susan J. Pritzel, BS, MA

School of Dentistry

University of Michigan

Ann Arbor, MI

\begin{abstract}
The purpose of this research was to identify dentist characteristics and dental office staffing patterns related to delegation of sealant applications. Results from a 1989 mailed survey were used to characterize Michigan general dentists $(\mathrm{N}=300$ ) who did or did not delegate sealant applications to auxiliaries and to identify factors associated with delegation. Nearly 50 percent of respondents were applying all sealants themselves. In offices that delegated the procedure, the mean proportion of sealants being applied by dentists was 39.9 percent. Registered dental hygienists were applying 51 percent, while registered dental assistants were applying 6.5 percent. Delegating dentists were more knowledgeable about sealant procedures, held more favorable attitudes, treated more young patients, placed more sealants, and were better informed about the legality of delegation according to the state practice act. Logistic regression analysis found that employing a registered dental hygienist was the most significant factor associated with sealant delegation, followed by employing a registered dental assistant. Findings suggest that dental auxiliaries, and particularly registered dental assistants, are underutilized for applying sealants. Approaches to increasing delegation of sealants may include changing dentists' traditional hiring patterns, highlighting the skills of auxiliaries such as the
\end{abstract}

Send correspondence and reprint requests to Dr. Lang, Department of Periodontics/Prevention/Geriatrics, School of Dentistry, University of Michigan, Ann Arbor, MI 48109-1078. Supported by the American Fund for Dental Health. Manuscript received: $5 / 26 / 92$; returned to authors for revision: 7/22/92; accepted for publication: $12 / 8 / 92$. registered dental hygienist $(R D H)$ and the registered dental assistant (RDA), and increasing awareness of legally allowable procedures that RDHs and RDAs can perform.

Key Words: fissure sealants, dental auxiliaries, delivery of health care.

Utilization of fissure sealants by dentists has slowly increased during the preceding two decades (1-4). Dentists' adoption of sealants as a new innovation may be nearing completion, but sealant use continues to be infrequent $(1,5,6)$. This circumstance has been attributed to many factors, including some related to dental auxiliaries. Limited delegation of sealant applications is a predominant theme that pervades auxiliary issues. Reasons for nondelegation include dentists' lack of knowledge about the legality of sealant delegation and the economic benefits of delegation $(7,8)$, dentists' low opinions about auxiliaries' abilities to apply sealants (3), and practice characteristics such as numbers of auxiliaries employed by dentists $(9,10)$. Furthering our understanding of these issues in order to increase sealant delegation seems worthwhile. But it may be instructive to review this premise that delegation of sealant applications is worthwhile - to provide a rationale for studying the subject.

We can evaluate this assumption by applying criteria for determining the efficiency of, and need for, delegating any dental task. Chapko offers three principles: (1) tasks 
that save the most time should be delegated; (2) if a task is delegated, it should be done consistently; and (3) the task should be delegated to the least expensive auxiliary (11). Tommasone (12) proposed other criteria: (1) delegation of the procedure should be within the law, (2) the procedure must be performed frequently, and (3) the dentist must be willing to delegate the procedure. Let us examine how well sealant delegation fits these criteria.

Is time saved by delegating sealant applications? There is a significant body of research on task delegation, but most investigations occurred at a time when few sealants were being applied (11,13-16). For example, Chapko (11) reported in 1985 that sealant applications were performed in only 0.2 percent of patient visits. Yet, it is noteworthy that of 14 frequently, and 16 infrequently, delegated tasks assessed by his study, acid etching and applying a sealant saved the dentist the most time (20 minutes) of any procedure. Regardless of time saved, dentists may still choose to perform a particular function themselves because there is no other task for them to perform (14).

Sealants can be consistently delegated. In fact, the autonomous nature of sealant placement lends itself to consistent delegation. Also, delegation appears more likely if certain procedures can be grouped for a particular operator, such as preventive services performed by the dental hygienist (11). Incorporating sealant application into this service cluster seems reasonable. Nonetheless, dentists' expectations of traditional auxiliary responsibilities-hygienists performing only prophylaxes-may constrain them from considering new, unfamiliar duties (11). Auxiliary turnover may also affect decisions to delegate (15).

Sealants can be delegated to less expensive auxiliaries. A dental assistant can apply sealants at one-quarter the cost of a dentist while a dental hygienist can apply them at one-third the cost (17). Unfortunately, dentists' lack of knowledge about the economic benefits of delegating sealant application may be an inhibiting factor (18).

Sealant application can be legally delegated. For nearly a decade, sealant application has been a legal function of dental hygienists in 35 states, while 14 states have permitted formally trained dental assistants to apply sealants (19). However, allowable functions and descriptions of auxiliaries vary by state, and regulation language about sealant delegation may be vague. In Michigan, sealant application is not specifically identified as an allowable function of any auxiliary, but is permitted as a delegable intraoral procedure designated as the "application of anticariogenics after prophylaxis, when ordered by a licensed dentist." This ambiguity may deter dentists from allowing their auxiliaries to apply sealants. By contrast, other states clearly specify that pit and fissure sealants may be applied by dental assistants with advanced training $(20,21)$. It has been observed that dentists practicing in states that allow delegation place more sealants than dentists in states not allowing delegation (7), but this situation has not been seen consistently with hygienists (22).

As previously noted, sealant usage continues to be infrequent $(1,5,6)$. Evidence of links between delegation and increased sealant use is limited, but generally there is consensus that sealant applications would increase if delegation were encouraged $(7,22,23)$. An indirect link is supported by research demonstrating a positive relation between employment of hygienists and increased sealant use $(1,9,10)$.

Finally, dentists' knowledge about, and attitudes toward, delegation must be considered. Surveys in Minnesota and Wisconsin found that delegation of sealants to dental hygienists was not supported by office policy in 24 percent and 31 percent of offices, respectively (24). Even auxiliaries who have received formal sealant continuing education have reported that some of their dentist employers resisted delegation of the procedure (25). Dentists have indicated that they have not delegated because they preferred applying sealants themselves, felt their auxiliary personnel lacked the time to apply sealants, and believed that auxiliaries were not prepared nor motivated to perform the procedure $(3,26)$.

In summary, it appears that delegation of sealant applications to auxiliaries is desirable, but influenced by many factors. A decision to delegate may be affected by state dental regulations, by general issues of task delegation, by characteristics of dentists and their staffing patterns, and by provider knowledge and attitudes. As these elements are complex and often interrelated, a study was undertaken to examine some aspects of sealant delegation. The purpose of the research was to distinguish characteristics of delegating and nondelegating dentists and to determine which characteristics, if any, were most likely to be associated with delegation of sealant applications.

\section{Methods}

An opportunity to participate in a sealant education initiative was offered to 2,203 dentists in four areas of Michigan. The initiative has been described elsewhere (27). The four areas were selected as program sites based on geographical proximity and concentrations of dentists. General and pediatric dentists in these areas were surveyed on their attitudes and knowledge about sealants and frequency of sealant applications before the initiative. The response rate to this initial survey was 62 percent $(N=1,361)$. About two-thirds of the respondents were randomly selected to participate in the education component of the program (Education Group, $n=923$ ). Continuing education courses, videotapes, and materials were offered to this group by using repeated mailings. The remaining dentists (No Education Group, $n=438$ ) were not offered any materials until they had completed a follow-up survey performed 18 months after the pre- 
intervention survey. The population used for the current analysis is the No Education Group dentists. These subjects were questioned about their employment of auxiliaries, their knowledge of state laws regarding delegation, and their sealant delegation practices.

A 26-item questionnaire was developed that contained questions from previous surveys on sealant knowledge, attitudes, and use $(2,28,29)$. Demographic information was acquired on each respondent, including age, practice location, and year of graduation. Dentists were requested to indicate the types of auxiliaries employed in their practices and the numbers of years these auxiliaries had been employed. If sealants were being applied in a practice, respondents were asked to indicate the proportion of sealants applied by the following individuals: dentist, registered dental hygienist, registered dental assistant, and dental assistant, with the resultant total to equal 100 percent. Mean percents of sealant applications by staff type were developed from these data. The distribution of responses was strongly skewed toward the dentistapplying sealants most frequently. Thus, for further analyses, respondents were stratified into two groups based on whether or not 100 percent of sealants were applied by the dentist. Extent of sealant use was determined by asking respondents to estimate the proportion of all patients aged 18 years and younger that received sealants in their practice. Respondents were also asked to specify the types of teeth they routinely sealed.

A sealant knowledge score (nine questions) and a sealant attitude scale (six questions, Cronbach's alpha $=.63$ ) were constructed (27). Subjects were also asked to check off a list of which dental professionals could legally apply sealants in Michigan. Figure 1 displays the questions concerning knowledge, attitudes, and state regulations. In Michigan, the registered dental hygienist (RDH) and the registered dental assistant (RDA) are the only auxiliaries legally allowed to place sealants (30).

Nonresponse analysis was performed by comparing nonrespondents to the first survey with the No Education Group that responded to the first survey. Age and location of these subjects were compared. With the second survey, No Education Group nonrespondents were compared to respondents on the variables of age, year of graduation, and location. Year of graduation was collected on the survey instrument.

Bivariate relationships of sealant delegation and individual independent variables were assessed separately using the Mann-Whitney $U$ test and chi-square statistic. The level of significance was set at $P<.05$. All significant variables were then used to construct a logistic regression model to identify factors associated with delegation. For the regression analysis, knowledge and attitude scores were dichotomized into high and low scores based on overall median scores of respondents. Six or fewer correct knowledge questions was considered a low score. An attitude scale value of 22 or less was considered a low
FIGURE 1

Knowledge, Attitude, and Delegation Questions

Knowledge Questions. Responses: Agree, Undecided,

Disagree. Score Range: 0-9.

1. Newly erupted permanent molars are the most important candidates for sealants.

2. Fluoride should be applied to the enamel surface immediately before a sealant procedure is initiated.

3. Loss of sealant is generally attributable to problems at the time of application.

4. As long as the sealant stays intact on the tooth surface, the sealed pit or fissure will not decay.

5. Enamel will become more susceptible to caries if a sealant is lost.

6. If the drinking water is adequately fluoridated, sealants aren't really needed.

7. Dental auxiliaries, when adequately trained, can apply sealants effectively.

8. Current research demonstrates that sealants are not retained for more than three years.

9. It is more cost-effective to have dental auxiliaries rather than dentists place sealants.

\section{Attitude Questions. Responses: Strongly Agree to Strongly} Disagree. Scale Range: 6-30.

1. Sealants are of great value in preventing caries.

2. Sealants are difficult to apply.

3. Sealants are easy to promote to patients.

4. More time is involved in applying sealants than amalgams

5 . Sealants are not practical in the private office setting.

6. Sealants can be used to arrest the progress of incipient occlusal caries.

Legality of Sealant Delegation in Michigan.

Which of the following professionals can legally place sealants in Michigan? Check all that apply.

1. Dentist

2. Registered dental hygienist

3. Registered dental assistant

4. Dental Assistant

5. I don't know

attitude score. Forward stepwise variable selection was used to develop a final regression model, and classification tables were used to assess the fit of the model by comparing predictions to observed outcomes (31). This final model was achieved after performance of a series of regression analyses with combinations of the seven variables found to be significant by Mann-Whitney $U$ and chi-square tests. Odds ratios and confidence intervals were developed for variables in the final model.

\section{Results}

A total of 358 dentists returned surveys ( $82 \%$ response rate). Surveys that were incomplete, from dentists in institutional settings, and from dentists in specialties not using sealants were excluded, resulting in 343 subjects. 
Nonresponse analysis was performed using these subjects. Pediatric dentists were excluded. Responses from general dentists who had indicated their delegating practices $(n=300)$ were examined. Numbers of subjects displayed in subsequent tables vary because some respondents did not complete all questions.

As seen in previous analyses (32), nonrespondents to survey one were older and less likely to be practicing in urban areas than the No Education Group dentists (the group of interest). In the second wave of surveying, No Education Group respondents and nonrespondents were

TABLE 1

Mean Proportion of Sealant Applications by Staff in Offices that Delegated $(n=154)$

\begin{tabular}{|c|c|c|}
\hline Individual Applying Sealant & $\%$ & SD \\
\hline Dentist & 39.9 & 33.4 \\
\hline Dental hygienist & 50.8 & 35.4 \\
\hline Registered dental assistant & 6.5 & 16.2 \\
\hline Dental assistant & 2.8 & 12.8 \\
\hline
\end{tabular}

similar in median age, median years since graduation, and geographic location. Based upon nonresponse findings from survey one and respondents' interest in further education, the final population must be considered somewhat select.

Regarding sealant applications, 47 percent of the respondents $(n=146)$, did not delegate the procedure. Table 1 shows the mean proportions of sealant applications being applied by individuals in offices where delegation of the procedure was occurring. One-half of all sealants were applied by dental hygienists. Dentists were applying about 40 percent of the sealants. Registered dental assistants were applying 6.5 percent of the sealants, and about 3 percent of sealants were being applied by nonlicensed dental assistants, although this practice is illegal.

Table 2 compares characteristics of dentists who delegated and those who did not delegate. Dentists who delegated were younger, their median age being 39.0, compared to 41.0 years for dentists who applied all sealants themselves. Differences in years since graduation were not statistically significant. Nearly all dentists who delegated sealant applications employed a registered dental hygienist (RDH), while only 79 percent of non-

TABLE 2

Characteristics of Dentists by Delegation Status

\begin{tabular}{|c|c|c|c|c|c|}
\hline Characteristic & Dentist Delegates & $n$ & Dentist Does Not Delegate & $n$ & $P$ \\
\hline \multicolumn{6}{|l|}{ Demographics } \\
\hline Median age (years) & 39.0 & 154 & 41.0 & 146 & $.04^{*}$ \\
\hline Median years since graduation & 12.0 & 152 & 14.0 & 144 & $.09^{*}$ \\
\hline \multicolumn{6}{|l|}{ Practice parameters } \\
\hline \multicolumn{6}{|l|}{ Dental hygienist } \\
\hline \% employing RDH & 98.7 & 153 & 79.0 & 138 & $<.001 \dagger$ \\
\hline No. years employed & 9.0 & 149 & 9.0 & 107 & .66 \\
\hline \multicolumn{6}{|l|}{ Registered dental assistant } \\
\hline \% employing RDA & 76.2 & 122 & 37.4 & 107 & $<.001 t$ \\
\hline No. years employed & 7.0 & 87 & 6.0 & 39 & .58 \\
\hline \multicolumn{6}{|l|}{ Dental assistant } \\
\hline \% employing DA & 97.9 & 144 & 93.8 & 128 & $.08+$ \\
\hline No. years employed & 10.0 & 138 & 8.0 & 118 & .82 \\
\hline Median no. patients $\leq 18$ years old / week & 15.0 & 148 & 12.0 & 141 & $.002^{*}$ \\
\hline $\begin{array}{l}\text { Median \% younger patients who } \\
\text { receive sealants }\end{array}$ & 15.0 & 125 & 9.0 & 142 & $<.001^{*}$ \\
\hline $\begin{array}{l}\text { Median value; sealant knowledge score } \\
\text { (range }=0-9)\end{array}$ & 7.0 & 154 & 6.0 & 146 & $<.001^{*}$ \\
\hline $\begin{array}{l}\text { Median value; sealant attitude scale } \\
\text { (range }=6-30)\end{array}$ & 24.0 & 153 & 22.0 & 143 & $.002^{*}$ \\
\hline \multicolumn{6}{|l|}{ Types of teeth sealed } \\
\hline Permanent molars (\%) & 99.4 & 154 & 95.2 & 146 & $.06+$ \\
\hline Premolars (\%) & 55.2 & 154 & 46.6 & 146 & $.17+$ \\
\hline Primary molars (\%) & 16.9 & 154 & 11.6 & 146 & $.29+$ \\
\hline
\end{tabular}

*Mann-Whitney U test.

tChi-square test. 
TABLE 3

Knowledge of State Regulations Regarding Sealant Applications

\begin{tabular}{lccc}
\hline & \multicolumn{3}{c}{$\begin{array}{c}\text { Correct Affirmative } \\
\text { Responses (\%) }\end{array}$} \\
\cline { 3 - 4 } Possible Sealant & $\begin{array}{c}\text { Dentist Dele- } \\
\text { gates }(n=154)\end{array}$ & $\begin{array}{c}\text { Dentist Does Not } \\
\text { Delegate }(n=146)\end{array}$ & \multicolumn{1}{c}{$P^{*}$} \\
Providers & 94.8 & 88.4 & .07 \\
Dentist & 93.5 & 67.8 & $<.001$ \\
RDH & 36.4 & 16.4 & $<.001$ \\
RDA & 4.5 & 1.4 & .20 \\
DA & & &
\end{tabular}

*Chi-square test.

delegating dentists employed this auxiliary. There was no statistically significant difference in the number of years that either group had been employing an RDH. The difference in proportions of delegating and nondelegating dentists who employed RDAs was substantial. About three-quarters of delegating dentists employed this auxiliary, compared to only 37 percent of nondelegating dentists. Both groups had been employing RDAs for the least amount of time of any auxiliary; however, there was no statistically significant difference in employment length between the two groups. No statistically significant differences were found between the proportions of delegating and nondelegating dentists who employed a nonlicensed dental assistant, nor in the length of employment of that auxiliary.

Dentists who delegated sealant applications treated more patients 18 years of age or younger and placed sealants on a higher proportion of their younger patients. Respondents who delegated sealant applications also had higher knowledge scores and more favorable attitudes toward the procedure. Delegating dentists did not appear to be more likely than nondelegating dentists to apply sealants to a particular type of tooth. Nearly 100 percent of each group were applying sealants to molars, while about 50 percent of each group were applying them to premolars. Less than 20 percent of either group were applying sealants to primary teeth.

Respondents' knowledge of the state practice act regarding sealant delegation is displayed in Table 3 . About 12 percent of nondelegating dentists did not identify the dentist as a professional who could legally apply sealants in Michigan. For the RDH, only two-thirds of nondelegating dentists identified this individual as legally able to apply sealants. Both delegating and nondelegating respondents lacked knowledge about legal delegation of sealant application to the RDA. Only 36 percent of delegating dentists correctly identified the RDA as being allowed to apply sealants, while only 16 percent of nondelegating dentists identified this auxiliary correctly.
TABLE 4

Logistic Regression Model for Sealant Delegation and Its Classification Table

\begin{tabular}{|c|c|c|c|c|}
\hline $\begin{array}{l}\text { Model } \\
\text { Predictors }\end{array}$ & Coefficient & SE & $\begin{array}{l}\text { Odds Ratio } \\
(95 \% \mathrm{Cl})\end{array}$ & $P$ \\
\hline Employs RDH & 1.26 & 0.38 & $\begin{array}{c}3.52 \\
(1.66-7.48)\end{array}$ & $<.01$ \\
\hline Employs RDA & 0.63 & 0.16 & $\begin{array}{c}1.89 \\
(1.39-2.56)\end{array}$ & $<.001$ \\
\hline $\begin{array}{l}\text { Knowledge } \\
\text { score }\end{array}$ & 0.46 & 0.15 & $\begin{array}{c}1.58 \\
(1.17-2.14)\end{array}$ & $<.01$ \\
\hline
\end{tabular}

Classification table

\begin{tabular}{lccc} 
& \multicolumn{2}{c}{ Predicted } & \\
\cline { 3 - 3 } Observed & Delegated & Did Not Delegate & \% Correct \\
\cline { 3 - 4 } Delegated & 111 & 15 & 88.1 \\
Did not delegate & 55 & 48 & 47.1 \\
& & & Overall \\
& & 69.6
\end{tabular}

Few respondents in either group chose the dental assistant.

Forward stepwise variable selection was used to determine which, if any, of the seven significant variables from Table 2 -median age, percentage employing a hygienist, percentage employing an RDA, median number of young patients per week, median percentage of patients receiving sealants, knowledge score, and attitude scale value - would be retained in a logistic regression model of delegation status. For this analysis, the dependent variable (delegation status) was coded 1 if the respondent delegated sealants and 0 if the respondent did not delegate. Table 4 shows the final logistic regression model and significant factors related to delegation. Employing an RDH was the strongest factor related to sealant delegation, with an odds ratio of 3.52. Employing an RDA was the second strongest factor (odds ratio $=1.89$ ), while having more knowledge about sealants was the weakest, albeit still significant, factor related to sealant delegation (odds ratio $=1.58$ ). Classification tables were used to compare predicted to observed outcomes based on the final regression model. The classification table is also displayed in Table 4 . The model was more successful at predicting delegating dentists $(88.1 \%)$ than nondelegating dentists $(47.1 \%)$. Overall, correct predictions of delegation/nondelegation were made in 70 percent of the cases used in the analysis.

\section{Discussion}

Generalizations from these findings are limited by the voluntary nature of subject participation and the modest response rates to the surveys. Additionally, many variables were acquired by self-report, and thus should be 
interpreted with caution. Despite these limitations, some understanding about factors related to sealant delegation can be obtained from the data.

Almost half the dentists in this investigation were still applying all sealants themselves, confirming the persistence of dentists' preferences for personally applying sealants (3). Even among delegating dentists, only 60 percent of sealants were being applied by auxiliaries. A number of reasons for nondelegation can be postulated. Lack of knowledge about the legality of sealant delegation could inhibit delegation. Delegating dentists were more knowledgeable than nondelegating dentists about the legality of sealant delegation to RDHs. Both groups were generally unaware of the legality of sealant application by RDAs. Even if dentists are aware of regulations regarding delegation, they may be unsure of auxiliaries' capabilities to apply a sealant properly. Dentists' predilection to apply sealants themselves may be related to practice busyness or to convenience. In other words, dentists perform the procedure themselves to fill appointments or in a sequence of events that precludes the efficient use of auxiliaries. However, these assumptions are more compatible with delegable procedures related to operative dentistry. It is fairly clear why dentists would perform certain tasks such as placing bases and matrices or packing and carving amalgams, rather than delegate them. Sealant placement, which is a more autonomous procedure, would seem to be eminently more delegable. A more positive interpretation of Table 1 is that delegation of 60 percent of sealants is fairly reasonable-most sealants are being delegated. To change this distribution, efforts should be directed at encouraging dentists to delegate more if it suits their practice style and to especially increase delegation to RDAs.

The absence of RDAs is observed in respondents' reports of lower frequency of employment and fewer numbers of years employed. The RDA, even when employed by a delegating dentist, was being underutilized for applying sealants $(6.5 \%)$. Underutilization may be due to the fact that delegation to RDAs has only been allowed in Michigan since 1983, while hygienists have been able to apply sealants legally since 1978 . The low awareness among dentists of the RDA's capabilities is underscored by the lack of knowledge of state regulations exhibited by all dentists regardless of their delegation status.

Lack of employment of RDAs may be related to the general unavailability of this auxiliary and to traditional employment patterns in dental practices. Growth in numbers of auxiliaries has paralleled dentist production, with a plateau in graduates followed by declines, particularly among dental hygienists (33). The availability of dental auxiliaries has also probably been limited by declines in constant dollar weekly incomes for these individuals (33). Regarding typical employment patterns, a dentist might initially hire or train a dental assistant that cannot legally apply sealants or perform other restricted procedures. As demand for services increases, another auxiliary (usually an RDH) is hired to perform these procedures. Hiring an RDA may not be considered. An alternative and perhaps more favorable scenario would be initially to hire an RDA that can apply sealants, thus allowing more efficient delegation strategies to be implemented sooner.

In the final regression model, two of the retained independent variables related to employment of RDHs and RDAs. The bivariate analysis also identified substantial disparities between auxiliary employment patterns of delegating and nondelegating dentists. Nearly 100 percent of delegating dentists employed a hygienist, compared to only 80 percent of nondelegating dentists. Three-quarters of delegating dentists employed an RDA, nearly twice as many as nondelegating dentists. If increased delegation of sealant applications is deemed a worthy objective, then an approach to increasing sealant delegation could include marketing efforts that extol the value of trained auxiliaries and the various preventive services that can be delegated legally to these individuals. Thus, when a dentist recruits an auxiliary, he/she should be aware of the merits of expanded functions and should consider these attributes in the hiring process. As to merits, sealant placement appears to be one of the most time-saving delegable functions and logically fits within an already established combination of delegable prevention activities-prophylaxis, oral hygiene instruction, and oral inspections (11).

In our model, having more knowledge about sealants was another factor related to sealant delegation by dentists. However, traditional continuing education about sealants has had little effect on changing dentists' behaviors; a circumstance that may be due to the singular nature of the procedure or the methods of promotion $(27,34)$. Given the limited success of changing dentists' behaviors by providing general knowledge of sealants, it might be appropriate to focus education efforts on appropriate utilization of auxiliaries as a possible stimulus for increasing sealant application. There is support for the premise that an increase in sealant application would occur if delegation is encouraged $(7,22,23)$. In particular, employing more hygienists has been found to be positively associated with increased frequency of sealant use $(1,9,10)$. Further, joint educational experiences for dentists and their staffs should be encouraged to demonstrate the benefits of a "team" approach to providing preventive health care. Sealant application fits this activity well because so many individuals in an office can perform the procedure. Education could emphasize the value of delegation, its consequence for efficient health care provision, and cognizance of legal responsibilities and limitations of all care providers. Interestingly, Tilliss (25) reported that half of the hygienists who completed a continuing education course had no dialogue about sealants with their dentists before, during, or after the course. 
This finding suggests that good office communication may be another critical feature of team building that could affect the use of sealants.

While the adoption of fissure sealants nears completion, low frequency of application remains as a problem. Delegating sealant placement to trained office auxiliaries may contribute to its solution. To encourage delegation, strategies might include changing dentists' traditional hiring patterns, highlighting sealant application as an undeclared skill of registered dental hygienists and assistants, and increasing dentists' awareness of the legality of delegation according to local regulation. Through such efforts, dental offices may increase cost-effective delivery of preventive services to the public.

\section{Acknowledgments}

This research was supported by the American Fund for Dental Health.

\section{References}

1. Badner V, Rosenberg D. Dentist use patterns for pit and fissure sealants and topical fluorides. J Dent Educ 1986;50:656-60.

2. Gift HC, Frew RA. Sealants: changing patterns. J Am Dent Assoc 1986;112:391-2

3. Rubenstein LK, Dinius A. Dental sealant usage in Virginia. J Public Health Dent 1986;46:147-51.

4. Cohen $L_{i}$ Labelle A, Romberg E. The use of pit and fissure sealants in private practice; a national survey. J Public Health Dent 1988; 48:26-35

5. Cohen L, Romberg E, LaBelle A. The influence of dental practice characteristics on pit and fissure sealant use: a national survey. J Dent Pract Admin 1988;53:125-32.

6. Chapko MK. Time to adoption of an innovation by dentists in private practice: sealant utilization. J Public Health Dent 1991; 51:144-51.

7. Cohen L, Romberg E, LaBelle A. Pit and fissure sealant use in private practice: influence of state practice acts. Am J Public Health 1988;78:316-17.

8. Brown W, Charbeneau G. Consensus summary of the conference. In: Conference on pit and fissure sealants: why their limited usage? Chicago, IL: American Dental Association, 1981.

9. Faine RC, Dennen T. A survey of private dental practitioners' utilization of dental sealants in Washington State. J Dent Child 1986;53:337-42.

10. Gonzalez CD, Frazier P], Messer LB. Sealant use by general practitioners: a Minnesota survey. J Dent Child 1991;58:38-45.

11. Chapko MK, Milgrom P, Bergner M, Conrad D, Skalabrin N. Delegation of expanded functions to dental assistants and hygienists. Am J Public Health 1985;75:61-5.

12. Tommasone DW. Duty delegation. Dent Cin North Am 1974;18: 829-38.

13. Mullins MR, Kaplan AL, Mitry DJ, et al. Production-economic effects of delegation and practice size in a private dental office. J
Am Dent Assoc 1979;98:572-7.

14. Kaplan AL. Clinical quality and delegation in a private dental office utilizing expanded-function dental auxiliaries. J Public Health Dent 1980:40:118-25.

15. Mullins MR, Kaplan AL, Bader JD, et al. Summary results of the Kentucky dental practice demonstration: a cooperative project with practicing general dentists. J Am Dent Assoc 1983;106:817-25.

16. Bader JD, Kaplan AL, Lange KW, Mullins MR. Production and economic contributions of dental hygienists. J Public Health Dent 1984;44:28-34

17. Regan JE. The general practitioner's perception on sealant use. In Conference on pit and fissure sealants: why their limited usage? Chicago: American Dental Association, 1981:41-6

18. Horowitz AM, Frazier PJ. Issues in the widespread adoption of pit and fissure sealants. J Public Health Dent 1982;42:312-23.

19. Scheirton L. Training and educational needs in pit and fissure sealant application for graduate dental personnel: continuing education and certification courses. J Dent Educ 1984;48:66-74.

20. State of New Hampshire. The practice of dentistry. Concord: State of New Hampshire, 1989.

21. IdahoState Board of Dentistry. Regulations of the Idaho State Board of Dentistry. Boise: State of Idaho, 1992.

22. Nielsen-Thompson N, Boyer EM. Sealant application frequency. Clin Prev Dent 1988;10:17-22.

23. Gift H. Report of the 1982 preventive dentistry survey. Chicago: American Dental Association Health Foundation, 1984.

24. Duffy MB, Bernet JK, Chovanec GK, Majerus GJ, Frazier PJ, Newell KJ. Dental hygienists' knowledge, opinions, and use of pit and fissure sealants: a comparison of two states. J Public Health Dent 1987:47:121-33.

25. Tilliss T. Application of pit and fissure sealants: long-term effects of a one-day continuing education course. Dent Hyg (Chic) 1986;60: $300-3$.

26. Kaplan AL, Bader JD, Mullins MR, Lange KW. Measurement of effects of a state dental practice act on potential delegation and production in general dental private practice. J Public Health Dent 1983;43:161-7.

27. Lang WP, Farghaly MM, Woolfolk MW, Ziemiecki TL, Faja BW. Educating dentists about fissure sealants: effects on knowledge, attitudes, and use. J Public Health Dent 1991;51:164-9.

28. Simonsen RJ. Pit and fissure sealants: attitudes toward and use by dentists in Minnesota. Quintessence Int 1983;4:473-9.

29. Hunt RJ, Kohout FJ, Beck JD. The use of pit and fissure sealants in private dental practices. J Dent Child 1984;51:29-33.

30. Michigan Department of Licensing and Regulation. Administrative rules of the Michigan board of dentistry. Lansing: Michigan Department of Licensing and Regulation, 1989.

31. Norusis/SPSS Inc M. SPSS/PC+. Advanced statistics 4.0 for the IBM PC/XT/AT/ and PS/2. Chicago: SPSS Inc., 1990.

32. Lang WP, Farghaly MM, Faja BW, Ziemiecki TL, Woolfolk MW, Dennison JB. The effect of education upon dentists' utilization of fissure sealants. Ann Arbor: University of Michigan, 1989:1-144

33. Waldman $H$. Dental auxiliaries in a more favorable period for dentistry: numbers, income, and job prospects. Dent Assist 1987;,56: $21-4$.

34. Bader JD, Sams DH, ONeil EH. Estimates of the effects of a statewide sealant initiative on dentists' knowledge and attitudes. J Public Health Dent 1987;47:186-92. 